resonance of $\mathrm{E}^{\prime \prime} \mathrm{b}$ for $\mathrm{A}$. There is a slight variation among individuals of the same sex of a few semitones.

I use the Roman numerals I.-XII. to denote the twelve notes of the resonator scale. What the actual notes are in each voice will depend upon No. V., the resonance of A, towards which the other's have the same relation in all voices alike.

It must be remembered that this has to do only with the roice as shown in the act of whispering, the resonances being rerified by their effect upon tuning-forks, and has no relation to the pitch of the voice. The rocal cords alone determine whether the roice is soprano or contralto, tenor or hass. But the musical and rich qualities of the roice depend mostly upon the proper growth and use of the resonator, the training of which is necessary to all who have to use the voice more than in ordinary conversation. whether it be in singing or in public speaking.

There is, however, much acoustical work to be done with reard to the subject of resonance, which seems hitherto to have been somewhat neglected by physicists.

The Presinest thanked 1)r. Aikin for his valuable pilper. He thought all laryngologists owed him a debt of cratitude for his attempt to elucidate the physiology of the voice. The working nut of the sulject must necessarily fall to the laryngologist.

I)r. Locis TrRner (Fdinburgh) remarked that in Malays and Australian aborigines some of the resonating carities. such as the frontal sinuses, were alsent in a large proportion of ca-es. Ilid J)r. Aikin think that accounted for the rocal peculiarities of the races in question?

Dr. Arkis, in reply, explained that the part played by the nose in the resonation of the voice was of great importance to the sonority of the voice; hut the nose, being a cavity enclosed by bony walls, was beyond control with regard to movements, and therefore did not take part in the formation of the rowels.

\title{
A CASE OF BEZOLD'S COMPLICATION OF SUPPURATIVE MASTOIDITIS.
}

By Frnest Waggett, F.R.C.S. (London).

The escape of pus from the mastoid cells into the digastric groove is not an exceedingly rare occurrence, and yet in my experience of this complication a diagnosis is not usually arrived at until the physical signs have become well established and the case is far 
advanced. If the present instance has any claims upon your interest, they will depend upon the early stage at which the condition was recognised, and also upon certain diagnostic features which are important because conflicting.

The case was that of a male of thirty, who came to me on March ! complaining of a muco-purulent discharge from the right ear, which had persisted, with short intermissions, since an attack of influenza three months previously. Pain had been experienced at the onset, but not since.

On examination. a minute volcano-like perforation was seen in the anterior inferior quadrant, and a quantity of odourless muco-pus was expelled on politzerisation.

The case seemed to be one belonging to that simple category which only requires a free exit for the discharge in order to end speedily in arest. I therefore freely incised the membrane and asked his medical attendant to carry out the usual antiseptic treatment, coupled with politzerisation for a time in order to prevent reunion of the edges of my incision.

On the twentieth day the patient returned, complaining that within a week of his former visit he commenced to experience slight pain in the mastoid region, and that for the last few nights he had heen kept awake by pain in the occipital region.

Examination showed that my incision had healed, leaving only a minnte aperture for the escape of the discharge. which was now pure pus. His doctor reported that politzerisation had been carried out as suggested. Gross evidence of mastoid disease was wanting. No rigors, nausea, or vertigo had been experienced, and the general condition was good, but a "gas engine" timnitus was present, and there was marked indistinctness of the edge of the right optic disc.

After an unavoidable delay of twenty-four hours he came under constant supervision, when, for the first time, very slight odema and tenderness could be made out over an area the size of a threepenny bit exactly corresponding with the usual site of the exit of the martoid vein from the bone. The temperature was slightly raised, and though the jugular vein in the neck was free from tenderness, I felt fairly confident in making a diagnosis of sinus phlebitis. P'ressure and percussion over the mastoid antrum gave rive to no alnormal sensation. The membrane had been again freely incised.

(In the following day Dr. Law kindly saw the patient with me. by this time a very distinct swelling had developed over the site of the infra-auricular gland immediately behind the ramus of the 
jaw, and it now seemed fairly evident that the patient was after all merely suffering from an adenitis, secondary to the disease or surgical interference with the membrana tympani. It transpired that he was subject to frequent nocturnal emissions, a phenomenon which is often accompanied in neurasthenic subjects with marked occipital headache. It was therefore decided to await developments. making use merely of the simplest antiseptic remedies coupled with sedatives. I)uring the three following days the infra-iuricular swelling increased in size, became cedematous, and finally red, and presented all the characters of suppurative adenitis in this situation, as seen so often in young children. The small area of adema at the posterior edge of the mastoid had either disappeared or become merged in the more widespread cutaneous wdema. The temperature never rose above 100 '. and the patient was decidedly relieved of pain and distress.

On the following day I made a final examination before preparing to open the supposed glandular abscess. Bezold's phenomenon had been in my mind, and I had examined with this object in view on more than one occasion with negative results.

The swelling, limited anteriorly by the ramus of the jaw, was roughly circular and an inch in dianeter. Keeping my eye upon the membrana tympani through the speculum, I exercised firm pressure over the swelling, and not until I had done so for perhaps twenty seconds did the pus spurt out with considerahle force through the perforation, leaving no question as to the nature of the case.

It is, I presume, needless to insist upon the necessity of keeping an eye upon the drumhead while performing this experiment, for pus may be made to well freely from the orifice of the meatus in those cases which occur, in my experience only in young children, where an external collection of pus communicates with the lumen of the meatus through a dehiscence in the floor of the latter.

The history beingr comparatively short and the low-lying position of the perforation indicating an absence of ossicular caries, I decided to spare the contents of the tympanum and to perform the simple Schwartze operation as far as the base of the mastoid was concerned. The antrum proved to be very small and to lie a full inch from the surface, an explanation of the absence of tenderness and cortical periostitis. It contained a milky, inodorous pus. together with pale adematous mucous membrane. Evidence of caries of the bone was completely wanting. I opened and cleaned the aditus without disturbing the tympanic frame, and washed the tympanum with biniodide lotion through this route. 
After erasing the attachment of the sterno-mastoid muscle, I removed the whole of the mastoid process piecemeal with the exception of its posterior edge. The cells contained pus, but no carious bone. A fistula about three millimetres in diameter was discovered leading into the upper part of the digastric groove. There was no eridence pointing to caries or necrosis as the cause of this perforation of the roof of the fossa. The periosteal outer wall of the groove corresponding to the insertion of the digastric muscle was incised, and an abscess, into which a director had been passed through the fistula, was laid open and cleaned out. The abscess cavity was not larger than a filbert, and its long axis was directed forward into the parotid region, where a counter opening was made. The posterior part of the abscess occupied a plane immediately internal to the digastric muscle.

The usual precautions as to immediate cleansing and provision for subsequent drainage were taken, and on changing the dressing for the second time on the tenth day after operation, a healthy healing wound was found. Although under the circumstances it was not very surprising, still it is perhaps worth while to note, in these days of radicalism in surgery, that not only was the hearing normal, but the tympanic membrane was practically normal in appearance.

Within a month of operation the chasm produced by so extensive a removal of bone had healed by granulation and skinned over, and with the exception of an unsightly scar the ear is now none the worse for its disease and operation. The movements of the head seemed to be very little affected by the removal of the sterno-mastoid insertion.

I must now apologise for troubling you with the details of a case apparently so banal. My first excuse will be to make the proposition that it is undesirable to perform repeated politzerisation in cases of muco-purulent otorrhcea, where only a linear incision, or a perforation other than an extensive one, is the sole guarantee against the injection of the discharge into the mastoid antrum.

I am fully aware that the communication between the tympanum and the attic is usually minute and frequently absent. I confess that it has been $m y$ habit to make use of this manipulation in simple muco-purulent cases, but I was glad to hear Mr. Horsley condemn the practice a few weeks ago. In the case I have reported I am quite certain that the external attic at all events was free from disease before the politzerisation was instituted, and I have no doubt that the repeated inflation, coupled with an untimely 
reunion of the tympanic incision, was the cause of the mastoid infection which followed.

In the second place, I would suggest that the early development of extra mastoid suppuration without any evidence of caries or necrosis of the bone should keep the surgeon alive to the fact that the outer wall of some of the mastoid cells may be defective, or so thin as to be ruptured very readily under the pressure of retained pus, or possibly even by that induced during politzerisation where some part of the tortuous channel leading to the middle ear acts in a valvular manner.

A third point of interest was the occurrence of œdema and tenderness at the posterior border of the mastoid which simulated phlebitis of the mastoid vein, and led to an erroneous diagnosis. Events proved its occurrence to have been due to edema spreading backwards along the digastric groove, and I believe I am not incorrect in saying that aurists are not in the habit of looking for early indications of infection in this groove. I would venture to reiterate that the diagnosis of Bezold's phenomena, as far as I have met with it in practice or in literature, is not usually founded on early signs such as this, and it would, I think, be valuable if statistics could be collected as to the frequency of the occurrence of this posterior celema in the early stages of this complication.

A fourth point of interest in this case depends upon the close simulation of infra-auricular adenitis, which is, I believe, extremely uncommon, if not unique. As a rule, the pus is found tracking downwards along the course of the great vessels, and in the few cases I have had the good fortune to see has produced a swelling under the upper third of the sterno-mastoid muscle. In the present instance the pus made its way directly forwards in close contiguity with the branches of the facial nerve and the infra-auricular gland, and had Bezold's experiment given a negative result on a final trial, the abscess rould no doubt have been opened merely through the external route, and regarded as a suppurative adenitis. In this connection I would again draw your attention to the fact that no pus could be expelled from the tympanum until external pressure had been exerted for a considerable number of seconds. The question arises as to how long and with what degree of force may such pressure be exerted with safety. That considerable caution is necessary is proved by a case in Dr. Law's practice which I had an opportunity of examining. In that case one cell, or group of cells, had opened both into the sigmoid groove and externally, thus causing a large collection of pus in the neck to be in free communication both with the mastoid antrum and a large extradural 
abscess which extended inwards along the sigmoid groove as far as the jugular bulb. Undue external pressure under these circumstances might have been attended with serious consequences.

Finally, gentlemen, I would venture to enumerate the followin: points as perhaps worthy of discussion:

1. The question of politzerisation in muco-purulent otorrhua.

2. The escape of pus into the digastric groove in the absence of caries or necrosis.

3. (Edema and tenderness at the posterior extremity of the digastric groove, simulating phlebitis of the emissary vein.

4. The simulation of infra-auricular adenitis.

5. The necessity of observing the perforation while maling Bezold's experiment.

6. The question as to the duration and degree of the extronal pressure to be exercised.

\title{
THIRTEENTH INTERNATIONAL MEDICAL CONGRESS, PARIS.
}

\author{
August 2-9, 1900. \\ Section of Otology. \\ Summary of communications translated and abstracted by \\ Arthur J. Hutchison, M.P.
}

On a Unicersal Notation of Acoumetry. By Dr. F. Schiffens (Liège).

For several years attempts have been made by physicians and physiologists to invent a simple and practical acoumetric notation. The endeavour to invent a method which shall put the measurement of hearing acuity on the same level as the measurement of visual acuity is a legitimate endeavour, but it must be admitted that the problem is much more complex, and its solution is extremely difficult. Apart from the incompleteness of our knowledge of the physiology of hearing, the difficulty of the problem is increased by the fact that sound vibrations reach the perceptive apparatus by two distinct routes, the aerial and the bony. Further, the principal function of the ear is to perceive articulate language. We have, therefore, to deal not only with the special sense, but also with the faculty of appreciation and analysis, the comprehension of the complex sounds of the different words which succeed one another in a phrase. How can we possibly invent a simple and trustworthy notation of these? Daily experience with children demonstrates 